\title{
The Application of Visual Teaching Resources in Chinese Teaching in Schools for the Deaf*
}

\author{
Qin Liu \\ College of the Special Education \\ Leshan Normal University \\ Leshan, China 614000
}

\begin{abstract}
Through the investigation, it is found that there are some problems in the application of Chinese visualization resources in schools for the deaf: less visual teaching resources; less understanding of visual teaching resources by teachers; and lack of pertinence in the selected visual teaching resources. Based on this, in view of the low, middle and high Chinese Language Teaching of deaf students, it is found that the visual teaching resources can improve the enthusiasm and initiative of deaf students, the deaf students can participate in learning activities more actively, the ability of understanding and applying knowledge is enhanced, the academic achievement is obviously improved, and the effectiveness of classroom teaching is improved.
\end{abstract}

Keywords-visual teaching resources; deaf students; Chinese teaching

\section{INTRODUCTION}

Visual teaching resources are mainly used to convey abstract and complex teaching content in the way of visual representation. Chinese course is a comprehensive and practical course for learning the use of language and characters, and it is a tool for deaf students to communicate. With the rapid development of information technology, it will be helpful for deaf students to understand and master the learning content by means of visualization to transform the abstract knowledge in Chinese subject into the teaching content which is close to the intuitionistic image of students' life, so as to improve the teaching effect of deaf Chinese classroom. This study is aimed at Low, middle and high Chinese Language Teaching at different stages of study for deaf students, by using visual teaching methods, it promotes the learning and thinking of deaf students, thereby improving the effectiveness of classroom teaching.

\section{ApPlicAtion Status OF Visual TEACHING Resources In Chinese LANGUAGE TEACHING IN SCHOOLS FOR THE DEAF}

This study investigated a special education school. There are 5 classes for deaf students in the school, which are grade one, grade two, grade four, grade five and grade eight. There are 41 deaf students and 5 Chinese teachers in the class for

*Fund: Leshan Normal University's 2015 teaching reform project "construction and application of video case database of Chinese Language Teaching method in special school ", Project No.: JG 2015- YB 42. deaf students. Through interviews and classroom observation, the deaf students and Chinese teachers in the school were investigated.

\section{A. Problems Found in Investigation}

The results show that there are several problems in the application of Chinese Visual Resources in schools for the deaf:

First, there are few visual resources for deaf Chinese Teaching. At present, the visual teaching resources in general education schools are very rich, but the visual teaching resources for Chinese in schools for the deaf are relatively small. Some of the visual teaching resources do not meet the physical and mental characteristics of deaf students and the actual needs of life, and some of the visual teaching resources do not match the content of deaf Chinese Teaching materials. This makes the Chinese teachers in the deaf class lack of resources in the selection and use of visual teaching resources.

Second, teachers use less visual teaching resources. According to the survey, most of the teachers said that it took them both time and energy to make courseware for the preparation of visual teaching resources. Compared with the use of courseware for teaching, they are more inclined to choose to put the teaching content directly on the projection, multimedia booth, etc. for teaching, which is simple and convenient.

Third, in the middle and high learning stages, visual teaching methods are used in a single form. The survey found that the most commonly used visual resources for Chinese teachers in deaf classes are pictures and videos. For the deaf students in the low learning stage, the use of pictures, videos and so on can bring them good visual stimulation, mobilize their enthusiasm for learning, and through the connection of pictures and words, the deaf students can grasp the words learned more firmly. But for the deaf students in middle and high learning stage, it is more important to develop their logical thinking and abstract thinking. However, most teachers still use the visual resources commonly used in low learning stage, and never use the mind map for teaching. In addition, when some teachers use visual resources, they are not connected with the actual life of deaf students, or 
classroom. Therefore, in the design of teaching content, according to the characteristics of deaf students and the difference of teaching content, the appropriate visual form is choose according to the teaching needs.

\section{B. Suggestions on the Application of Visual Teaching Resources}

First, visual teaching resources are designed for deaf Chinese Teaching and deaf students' physical and mental characteristics. The development of deaf students' thinking is limited by the development of language; they are mainly concrete image thinking, good at remembering concrete things, but not good at remembering abstract content [2]. The purpose of using visual teaching resources is to visualize the abstract and complex Chinese Teaching content directly, so as to help the deaf students understand and master it and improve the efficiency of Chinese Teaching. Therefore, in the design of visual teaching resources, only in close combination with the content of deaf language teaching materials, fully considering the characteristics of deaf school language, the physical \& mental development characteristics of deaf students and the reality of life, which can achieve the purpose of promoting deaf students to understand and master knowledge.

Second, it is required to strengthen the training so as to improve the teachers' understanding of visual resources and the ability to use visual resources. The school can use collective training, or invite experts to explain and train the use of visual teaching methods, so that teachers can have a deeper understanding and recognizing of visual teaching resources, so that teachers can skillfully use them. In addition, teachers are encouraged to learn more about visual teaching resources through self-study, so as to improve their teaching ability.

Third, it is required to choose and apply visual teaching resources reasonably. When teachers choose and apply visual teaching resources, they must choose and use them pertinently. First, it is necessary to analyze the situation of the students in the class, and according to the characteristics of the physical and mental development of the deaf students and the actual life of the students, choose the teaching resources suitable for them. In addition, the teaching content is analyzed, and the appropriate visual teaching resources presentation mode is selected according to the characteristics of the teaching content.

\section{THE CONCRETE APPLICATION OF VISUAL TEACHING RESOURCES IN DEAF CHINESE CLASSROOM}

There are various forms of visual resources, each with its own advantages and characteristics. The commonly used forms of visual resources are as follows: multimedia courseware, network course, video resource, static wall map, sketch drawing, etc. [3]. The application of visual teaching resources in deaf Chinese Teaching is not as good as the more. It is necessary to design around the teaching objectives. For a certain purpose, the abstract and complex language and characters should be visualized directly, so as to arouse the deaf students' interest in learning, attract and maintain their attention, and help them better master and use the learning content, so as to improve the teaching effect of deaf Chinese

\section{A. The Application of Visual Teaching Resources in Deaf Chinese Language Teaching}

1) Taking the Chinese language teaching of deafness in the low stage as an example: Through pictures, images and videos, the text description in Chinese Teaching materials is transformed to make it more imagery and visibility, in line with the cognitive characteristics of deaf students, and can stimulate the curiosity and learning interest of deaf students [4]. The lower stage students are younger, have less knowledge and life experience, and have not experienced formal sign language learning before entering school, which makes it difficult for them to understand Chinese knowledge. Therefore, when applying visual resources, attention should be paid to combining the existing experience and life reality of deaf students.

For example, in the term of learning "tea table", the tea table is a kind of furniture which is common in the life of the deaf, and before the study, they also have a certain understanding of the physical object of the tea table, but it is still strange to the "tea table", for deaf students to fully understand the word, physical and graphic images can be used. Teachers can look for some pictures close to students' life, showing different tea tables of materials such as glass tea table, marble tea table, wooden tea table, and tea tables with different shapes such as round, square or other irregular figures, so as to help students build a more complete and clear concept of "tea table". As in the term of learning "rape", as the local culture of the north and south of China is different, the picture of "rape" in the textbook is different from that in the life of deaf students. The teachers need to select the appropriate graphic image according to their actual and local culture.

It is very important to lay a solid foundation of Chinese for the deaf students of low age. It is very necessary for the deaf students at low age to contact the Chinese subject, enhance their interest in learning Chinese and cultivate good Chinese learning habits. Driven by interest, they will actively explore and learn, so as to master the knowledge they have learned. Therefore, when the visual resources are applied, the content of the teaching is interesting and practical. For example, when learning the text "traffic lights", teachers can't only teach words. In daily life, deaf students have the experience of crossing the road, and have a certain understanding of "traffic lights", "crosswalk", etc. Therefore, in the teaching process, teachers can first play a video of crossing the road in life to attract the attention of deaf students, and let them pay attention to observe, which traffic lights in the video are they met in life, and let them say the traffic rules of the road. Deaf students are very interested in the things they often encounter in their daily life appearing in the video. In this way, they are more likely to focus on observation and thinking, which not only promotes their learning and understanding of words and sentences, but also 
enhances their awareness of complying with traffic rules, so as to achieve the purpose of organic combination of cognitive and emotional education.

2) Taking the middle stage deaf Chinese language teaching as an example: Middle deaf students have accumulated a certain amount of Chinese knowledge. Therefore, when designing visual teaching resources, teachers need to consider the reality of deaf students' life and combine the Chinese knowledge with the existing knowledge and life experience of deaf students. For example, when talking about the knowledge point of "how to write message correctly and normatively", teachers can create situations to make deaf students understand the concept of "message notes" and understand the correct writing format of "message notes". The deaf students have the right knowledge of the "message notes, and then create some specific situations for them to practice, thus to consolidate the learned knowledge. For example, in the teaching of the text Flying Kites, to make deaf students understand the word "all kinds", teachers can list the kites of different shapes in the article, and match them with corresponding pictures to show a lot of styles of kites, so as to better understand the meaning of the word "all kinds". After the deaf students understand the word, the teacher will show other pictures, such as commodities in the supermarket, stationery in the stationery shop, clothes in the clothing shop, vegetables and fruits in the vegetable market, etc., so that the deaf students can learn to use the word "all kinds" for the extended training of imitation and parody.

3) Taking a high-stage deaf-language teaching as an example: The ability of the cultivation of logical thinking has a great influence on the development of the ability of Analysis synthesis, reasoning and so on of the deaf. Abstract logical thinking of deaf students in high stage has developed to a certain extent, but it is still developing slowly. Therefore, it is very necessary to train their logical thinking. In the process of using visual teaching resources, it is necessary to fully stimulate their enthusiasm for learning, let them actively participate in teaching activities, actively think and learn to think, so as to promote the development of logical thinking and enhance the ability of Chinese learning. For example, when learning the text of Peanut, deaf students can be guided to show the context of the full text in a schematic way: "planting peanuts, collecting peanuts, tasting peanuts and talking about peanuts." When explaining the important and difficult content of "talking about peanuts", we deaf students can be guided to take "talking about peanuts" as the central point and present the content of "talking about" in the form of circle diagram, so as to sum up the quality and characteristics of peanuts. In understanding and refining the central idea, It can analyze the similarities and differences between "Peanut " and several other items in the article by drawing a chart, and then combine the characteristics and quality of peanut discussed earlier, so that deaf students can understand the truth of "to be useful, not only decent, but not good for others", so as to understand the central idea of this article. In teaching this article, according to the needs of teaching content, choose to use graphics and images, choroid map, table, multimedia courseware and other different forms of visual resources, guide deaf students to actively participate in the classroom, positive thinking, promote deaf students to grasp the knowledge points, also the training of thinking ability, pay attention to the development of students' cognition and thinking.

\section{B. Application and Analysis of Visual Teaching Resources in Deaf Chinese Teaching}

1) Application effect: According to the results of classroom feedback and after class test of deaf students, in the process of using visual resources for teaching, the classroom atmosphere is active, and they can more actively participate in classroom activities; for the questions in the classroom, most deaf students can actively think and raise their hands to answer questions; they make fewer small movements in the classroom, and keep their attention longer; For the new words learned, most deaf students can understand and remember them accurately in the process of dictation and use of words; When using visual teaching resources to explain sentences or texts, some deaf students understand more easily and pay more attention to them. In the process of testing, it is found that most deaf students can better understand and apply the knowledge they have learned, and the course performance has been improved. It can be seen from the feedback results of deaf students that they prefer visual teaching methods more than traditional Chinese Teaching methods. Therefore, the application of visual teaching resources has played a positive role in teaching effect of deaf Chinese.

2) Effect analysis: From the perspective of the students, the visual resources of the choice and application are in accordance with the learning characteristics of the deaf and the requirements of the teaching goal, and the learning needs of the deaf students are satisfied. As a result, in the aspect of the classroom performance of the deaf, they will feel more relaxed and happy in the process of learning, and can be more actively integrated into the classroom and participate in the class. In a lively and pleasant atmosphere, they are of interest and are willing to be actively involved in the learning activities, and the efficiency of learning has improved accordingly.

From the perspective of teachers' classroom teaching situation, the application of visual teaching resources reduces the burden of teachers' teaching to a certain extent. The teacher's teaching method based on teaching has been transformed into the teaching method that teachers guide deaf students to observe and think mainly. Students take the initiative to participate in the classroom, demonstrating the concept of "student-oriented". Chinese teachers in the class of deaf students generally believe that visual teaching resources can meet the learning characteristics and needs of 


\section{REFERENCES}

deaf students, help to resolve the more abstract and complex teaching content, and help to improve the effect of Chinese Teaching.

\section{CONCLUSION AND REFLECTION}

The application of visual teaching resources in deaf Chinese class can bring positive influence on deaf students' Chinese learning. However, the deaf students may not be familiar with visual teaching methods and visual tools, and their learning efficiency will be affected. Therefore, before visual teaching, teachers need to guide deaf students to change their way of thinking and learning, and flexibly use visual resources for learning. When applying visual resources, pay attention to the following:

\section{A. Respecting the Discipline of Chinese Language \\ Teaching}

Chinese in schools for the deaf is a comprehensive and practical course that focuses on the understanding and application of language and characters. That is, when applying visual teaching resources, it is necessary to grasp the characteristics of the Chinese discipline, make full use of the content and characteristics of the Chinese discipline, visualization teaching cannot be carried out just for the use of visual resources.

\section{B. Following the Practicality of Chinese Language \\ Teaching}

The purpose of using visual Chinese Teaching resources in schools for the deaf is to help deaf students understand the more complex and abstract teaching content in the process of Chinese learning and improve the effect of Chinese Teaching in schools for the deaf. Therefore, when designing visual teaching resources, it is necessary to follow the principle of practicability, which must meet the characteristics of physical \& mental development and learning needs of deaf students, as well as the characteristics of Chinese Teaching in schools for the deaf.

\section{Following the Openness of Chinese Language Teaching}

Chinese subject knowledge is closely connected with all aspects of social life. Chinese is reflected everywhere in life and learning. When designing visual teaching resources, teachers should consider more about the integration of Chinese subjects and other subjects; the combination of Chinese Language Teaching and social life, so that the appropriate Chinese Language Teaching resources in social life can be integrated into Chinese classroom teaching; Linking Chinese language education in general and schools for the deaf, and enriching schools for the deaf by referring to the excellent Chinese Teaching resources in general school language and adapting appropriate general language teaching resources to the characteristics of deaf students Chinese Language Teaching resources.
[1] Chinese Course Standards for Deaf School Compulsory Education (2016 Edition). Formulated by the Ministry of Education of the People's Republic of China. (in Chinese)

[2] Wang Ling, Xiao Qiang. Pay attention to the cognitive characteristics of deaf students and generate high-quality mathematics classroom [J]. Western China (second half of the month), 2007, (05): 246. (in Chinese)

[3] Zheng Man. Research on visual teaching resources for deaf students [D]. Henan University, 2013: 39-45. (in Chinese)

[4] Sun Minyan. Several Thoughts on Computer Technology in the Chinese Language Teaching of Deaf and Dumb Schools [J]. Chinese Language Construction, 2016, (03): 23-24. (in Chinese) 